\title{
KAJIAN FRASA "MEMBINASAKAN BAIT ALLAH" BERDASARKAN 1 KORINTUS 3:10-32 DAN \\ IMPLIKASINYA BAGI JEMAAT KRISTEN MASA KINI
}

\author{
Herodion, Robi Panggarra
}

\begin{abstract}
Abstrak
Sesuai dengan pokok masalah yang ada, maka yang menjadi tujuan dalam penulisan skripsi ini adalah: Pertama, untuk mengetahui tentang kajian frasa "membinasakan bait Allah" seperti yang dijelaskan dalam 1 Korintus 3:17. Kedua, untuk memberikan gambaran implikasi dari kajian frasa "membinasakan bait Allah" dalam kehidupan Jemaat Kristen masa kini. Metode penelitian yang digunakan dalam penulisan skripsi ini adalah metode Hermeneutik Eksegesis kualitatif. Metode ini menentukan analisis konteks, genre, analisis struktur, menguraikan anaisis teks dan menganalisis teks tersebut dengan menggunakan metode pengumpulan data melalui penelitian kepustakaan dengan menggunakan Alkitab sebagai sumber utama, dan didukung dengan kamus, buku-buku dan jurnal serta berbagai literatur berhubungan dengan pembahasan penulis. Dari hasil penelitian ini, penulis menarik kesimpulan: Pertama, bait Allah dalam konteks 1 Korintus 3:17 ini bukan merujuk kepada seseorang atau satu orang saja namun merujuk kepada kumpulan orang-orang percaya yang telah dikuduskan dan dikhususkan oleh Allah. Kedua, bait Allah jangan dihancurkan dengan memasukkan ajaran sesat dan hikmat dunia kedalamnya, siapa saja yang melakukan hal tersebut akan berurusan dengan Allah. Implikasi dari kajian frasa "membinasakan bait Allah" bagi jemaat Kristen masa kini adalah: Pertama, jemaat Kristen masa kini harus hidup sesuai ajaran firman Tuhan. Kedua, hidup dalam kerendahan hati. Ketiga: hidup dalam hikmat Allah.
\end{abstract}

Kata-kata Kunci: Membinasakan, Bait Allah, 1 Korintus 3:10-23

\section{Latar Belakang Masalah}

Kehadiran Bait Allah bagi bangsa Israel sebenarnya bukan pada saat Raja Daud merencanakan untuk membangunnya (1 Taw. 22:2-19) setelah Allah berfirman kepada nabi Natan agar memberitahu raja Daud untuk mendirikan rumah Tuhan (2 Sam. 7:1-17), ataukah pada saat Raja Salomo telah mendirikannya (1 Raj. 7; 2 Taw. 3), melainkan pada waktu Allah menyuruh Musa pada saat berada di gunung Sinai untuk membuat tempat kudus bagi Tuhan yaitu Kemah Suci (Kel. 25:8-9). ${ }^{1}$ Kemah Suci dan Bait Allah memang dua hal yang berbeda, Kemah Suci didirikan pada zaman Musa sedangkan Istilah Bait Suci atau Bait Allah itu muncul setelah Salomo membangunnya. Salah satu perbedaannya juga adalah Kemah Suci dapat berpindah-pindah sedangkan Bait Suci itu menetap. Namun Kemah Suci dan Bait Allah itu sama dalam hal maknanya, yaitu kehadiran Allah di tengahtengah umat-Nya.

\footnotetext{
${ }^{1}$ Herman Lesmana dan Robi Panggarra, "Makna Bait Allah dalam 1 Korintus 3:16-17 dan Implikasinya bagi orang Percaya Masa Kini," Jurnal Jaffray 12, no. 1 (2 April 2014): 129, Diakses 18 Februari 2019. https://doi.org/10.25278/jj71.v12i1. 35.
} 
Salomo mulai membangun Bait Suci pada bulan Zif (bulan kedua) tahun keempat pemerintahannya, dan menyelesaikannya pada bulan Bul (bulan kedelapan) tahun ke11 pemerintahannya; sehingga Bait Suci selesai dibangun dalam 6 tahun 6 bulan (1 Raj. 6:1, 37-38). Bait Suci Salomo adalah Bait Suci permanen pertama yang dibangun dalam sejarah (2 Sam. 7:5-7). Bait Suci ini dibangun di gunung Moria di mana Abraham mempersembahkan Ishak (Kej. 22:2), di tempat pengirikan Ornan di mana Daud mempersembahakan korban bakaran dan korban keselamatan (2Taw 3:1). ${ }^{2}$

Bait Suci Salomo yang luar biasa itu terletak di bukit Timur, sebelah Utara kota Daud, dekat dengan situs Dome of the Rock (Qubbe es-Sakhara) masa kini yang dibangun pada tahun 691 M. ${ }^{3}$ Allah berdiam di dalam Bait Allah bangsa Israel, berkuasa atasnya dan menempatinya, melalui awan kemuliaan yang menjadi tanda hadirat-Nya di antara bangsa itu. Bait Allah pada bangsa Yahudi itu diabdikan dan disucikan khusus bagi Allah, dan dipisahkan dari tujuan-tujuan umum lainnya serta diperuntukkan khusus bagi tujuan suci saja, untuk beribadah kepada Allah secara langsung. ${ }^{4}$

Paulus adalah seorang Yahudi dan dididik dengan teliti di bawah pimpinan Gamaliel dalam hukum nenek moyang mereka yaitu hukum taurat, dia juga seorang yang giat dalam pekerjaan Allah (Kis. 22:3). Melihat latar belakang kehidupan Rasul Paulus, bisa dipastikan bahwa ia mengetahui banyak tentang taurat. Itu sebabnya Paulus sering kali mengutip ayat-ayat dari Perjanjian Lama. Dalam 1 Korintus 3 Rasul Paulus mulai menasihati dan menegur jemaat di Korintus karena perselisihan yang terjadi di antara mereka. Ia memperingatkan jemaat bahwa mereka sebagai bangunan sebetulnya adalah Bait Allah yang kudus. ${ }^{5}$

Rasul Paulus mengatakan dalam 1 Korintus 3:16 bahwa mereka adalah bait Allah dan Roh Allah diam di dalam mereka. Satu perkataan tegas yang dikatakan oleh Paulus dalam menegur jemaat di Korintus yaitu dalam ayat selanjutnya di 1 Korintus 3:17 "Jika ada orang yang membinasakan bait Allah, maka Allah akan membinasakan dia. Sebab bait Allah adalah kudus dan bait Allah itu ialah kamu". Dalam pembahasan ini, penulis ingin membahas tentang makna dari pada frasa "membinasakan bait Allah".

Ada beberapa pandangan orang yang berbeda melihat ayat ini antara lain: Menurut Paul Ellingworth dan Howard Hatton dalam bukunya yaitu Pedoman Penafsiran Alkitab surat Paulus yang pertama kepada jemaat di Korintus mengatakan bahwa kata "membinasakan" dapat diartikan mencemari atau merusak. ${ }^{6}$ Menurut Billy Kristanto kata "membinasakan bait Allah" berarti menghancurakan Gereja-Nya, mereka diumpamakan seperti perngajar-pengajar palsu yang akan menyesatkan dan merusak kehidupan berjemaat. ${ }^{7}$ Sedangkan menurut David Ibrahim dalam bukunya "pelajaran surat 1 Korintus" mengatakan frasa "membinasakan bait Allah" berarti merusakkan dengan menimbulkan perpecahan, pengajaran yang sia-sia, menajiskan dengan perkara-perkara yang jahat, percabulan, minum minuman keras dan lain-lain dan hal tersbut menajiskan

\footnotetext{
${ }^{2}$ Abraham Park, Imam Besar Kekal yang Dijanjikan dengan Sumpah (Depok: Yayasan Damai Sejahtera Utama, 2017), 203.

${ }^{3}$ Philip J King, Kehidupan orang Israel Alkitabah (Jakarta: BPK Gunung Mulia, 2010). 377.

${ }^{4}$ Matthew Henry, Tafsiran Matthew Henry SURAT ROMA, 1 \& 2 KORINTUS (Surabaya: Momentum, 2015), 545

${ }^{5}$ Roger Dean Anderson, Tafsiran Perjanjian Baru Surat 1 Korintus (Surabaya: Momentum, 2018), 82.

${ }^{6}$ Paul Ellingworth dan Howard Hatton, Pedoman Penafsiran Alkitab Surat Paulus Yang Pertama Kepada Jemaat di Korintus (Jakarta: LAI, 2010), 89.

${ }^{7}$ Billy Kristanto, Ajarlah Kami Bertumbuh (Surabaya: Momentum, 2009), 45.
} 
dan mengotori bait Allah. ${ }^{8}$ Sedangkan menurut Warren W. Wiersbe kata "membinasakan" adalah menghancurakan bait Allah dengan memakai bahan-bahan yang berkualitas rendah. ${ }^{9}$ Mungkin maksudnya adalah ketika ada yang memakai bahan-bahan yang berkualitas rendah itu dapat menghancurkan bait Allah.

Marion L. Soards menjelaskan dalam bukunya: Baris terakhir dari pasal 3 ini adalah pernyataan mengejutkan yang mengganggu para penafsir karena pasti telah mengganggu jemaat Korintus yang pertama kali mendengar atau membacanya. Ayat ini adalah pokok bahasan teologis yang rumit tentang kualitas keselamatan yang kekal dan keamanan orang percaya. Tapi, karena Paulus tidak tahu apa-apa tentang masalah itu dalam surat ini, orang tidak boleh menekan pernyataan ini untuk membentuk resolusi bagi debat-debat itu. Memang, seorang tidak dapat mengatakan apakah kata Paulus "jika" mengacu pada realitas yang ia tahu atau perkembangan yang ia takuti dan cenderung menggagalkan. Sementara sifat tepat dari pernyataan Paulus tidak terbukti dengan sendirinya. ${ }^{10}$

Melalui pernyataan Rasul Paulus ini yaitu apakah membinasakan (Arti bahasa Indonesia) adalah kata yang tepat untuk hal ini? Ketika membinasakan adalah kata yang tepat, dengan cara apakah mereka dikatakan membinasakan bait Allah? Apakah dengan minuman keras, rokok, narkoba dan lain-lain adalah tindakan yang termasuk membinasakan Bait Allah? Dan ganjaran ketika mereka membinasakan bait Allah adalah Allah sendiri akan membinasakan mereka (1 Kor. 3:17). Apakah Tuhan akan membinasakan mereka yang membinasakan bait Allah? Jika ya, berarti Tuhan tidak mengampuni orang yang membinasakan bait Allah? Berdasarkan hal tersebut, maka penulis terdorong untuk mengangkat judul: KAJIAN FRASA "MEMBINASAKAN BAIT ALLAH" BERDASARKAN 1 KORINTUS 3:10-23 DAN IMPLIKASINYA BAGI JEMAAT KRISTEN MASA KINI.

\section{Pokok Masalah}

Berdasarkan latar belakang masalah di atas, maka yang menjadi pokok masalah dalam skripsi ini, yaitu:

Pertama, apa makna frasa perkataan Rasul Paulus tentang "Membinasakan Bait Allah" berdasarkan 1 Korintus 3:10-23?

Kedua, bagaimana implikasinya bagi kehidupan Jemaat Kristen masa kini?

\section{Tujuan Penelitian}

Penulisan ini selain bertujuan untuk memenuhi persyaratan akademik dalam rangka penyelesaian studi di Sekolah Tinggi Filsafat Jaffray Makassar, juga memiliki beberapa tujuan yang ingin dicapai:

\footnotetext{
${ }^{8}$ David Ibrahim, Pelajaran Surat 1 Korintus (Jakarta: Mimery Press, 1999), 54.

${ }^{9}$ Warren W. Wiersbe, Hikmat Di Dalam Kristus (Bandung: Kalam Hidup, 2001), 55.

${ }^{10}$ Marion L Soards, Understanding the Bible Commentary Series 1 Corinthians (United States of America: Baker Books, 2011), 75.
} 
Pertama, untuk mengetahui tentang kajian frasa "Membinasakan Bait Allah" berdasarkan 1 Korintus 3:10-23

Kedua, untuk menjelaskan implikasi dari kajian frasa "Membinasakan Bait Allah" dalam kehidupan Jemaat Kristen masa kini.

\section{Manfaat Penelitian}

Adapun manfaat dari penulisan tentang kajian frasa "Membinasakan Bait Allah" adalah sebagai berikut:

Pertama, sebagai dasar pemikiran bagi pembaca supaya memahami dengan benar tinjauan frasa "Membinasakan Bait Allah" berdasarkan 1 Korintus 3:10-23 dan implikasinya bagi Jemaat Kristen masa kini.

Kedua, agar tulisan ini dapat menjadi pedoman atau bahan pelajaran bagi penulis di dalam pelayanan dan juga diharapkan dapat menambah khazanah pengetahuan teologi, khususnya bidang kajian Teologi Biblika kitab Perjanjian Baru.

Ketiga, untuk memenuhi syarat untuk menyelesaikan Strata Satu (S1) Program Studi Teologi Kristen di Sekolah Tinggi Filsafat Jaffray Makassar.

\section{Metode Penelitian}

Adapun metode yang digunakan dalam penulisan ini adalah sebagai berikut:

Pertama, metode penelitian kualitatif atau Library Research di mana penulis meneliti dan mengumpulkan tafsiran dari buku-buku yang relevan dengan pokok bahasan di atas. Penulis melakukan penelitian kualitatif karena melalui penelitian kualitatiflah yang dapat membantu penulis dalam menemukan dan menjelaskan makna frasa "membinasakan bait Allah" berdasarkan 1 Korintus 3:10-23. ${ }^{11}$

Kedua, metode hermenutik dengan mengeksegesis menggunakan buku-buku, seperti Alkitab, Kamus, dan buku-buku yang lain yang berkaitan.

Ketiga, Penulis juga mencari data-data lewat internet seperti pencarian jurnal, buku-buku online dan arti-arti kata.

\section{Batasan Penelitian}

Dalam penulisan ini, penulis memberikan batasan tentang kajian frasa "Membinasakan Bait Allah" berdasarkan 1 Korintus 3:10-23. Adapun tafsiran-tafsiran serta teori-teori yang berkembang mengenai pokok bahasan penulis hanyalah sebagai referensi guna memperoleh pemahaman mengenai hal-hal yang ingin diketahui sesuai dengan pokok permasalahan di atas.

\footnotetext{
${ }^{11}$ Rajo, 144.
} 


\section{Sistematika Penulisan}

Sitematika penulisan skripsi ini terdiri dari 5 bab yang diklarifikasian sebagai berikut:

Bab pertama, merupakan pendahuluan yang terdiri dari latar belakang masalah, pokok masalah, tujuan penelitian, manfaat penelitian, metode penelitian, batasan penelitian dan sistematika penulisan.

Bab kedua, merupakan pembahasan tentang gambaran latar belakang Surat 1 Korintus yang terdiri dari gambaran umum Surat 1 Korintus, alasan penulisan, penulis, tempat dan tahun penulisan, tema umum, genre, garis besar tentang surat 1 Korintus.

Bab ketiga, memaparkan eksegesis surat 1 Korintus 3:17 tentang kajian frasa "Membinasakan bait Allah"

Bab keempat, adalah bab yang berisi implikasi teologis dan implikasi praktis makna membinasakan

Bab kelima, kesimpulan dan saran-saran

\section{Kesimpulan}

Dengan memperhatikan bab-bab sebelumnya, maka penulis menarik beberapa kesimpulan, antara lain:

Pertama, bait Allah dalam konteks 1 Korintus 3:17 bukan merujuk kepada seseorang atau satu orang saja, namun merujuk kepada kumpulan orang-orang percaya yang telah di kuduskan dan dikhususkan oleh Allah, dimana dalam jemaat tersebut, Allah berdiam di dalamnya.

Kedua, bait Allah jangan dibinasakan, hal ini diperuntukkan untuk orang-orang yang ingin menghancurkan bait Allah yaitu jemaat Allah, dengan cara menghancurkan sehingga akan timbul perselisihan dan perpecahan dalam jemaat, bahwa ada konsekuensi yang akan terjadi apabila ada seseorang yang mau menghancurkan bait Allah, yaitu hukuman dari Allah. Orang-orang yang ingin merusakkan jemaat Allah, akan berurusan dengan Allah.

Adapun makna dari membinasakan bait Allah antara lain:

Pertama, menghancurkan dengan ajaran sesat. Ajaran sesat dapat dengan mudah untuk menghancurkan jemaat Korintus, apalagi jemaat Korintus pada saat itu masih tergolong memiliki kerohanian yang rendah, hal itu ditandai dengan perkataan Paulus bahwa susulah yang diberikan kepada mereka, bukan makanan keras (1 Kor. 3:2). Tantangan jemaat mula-mula, termasuk di dalamnya jemaat Korintus pada saat itu adalah pengajar-pengajar sesat. Mereka berusaha untuk menghancurkan jemaat Korintus dengan ajaran sesat, mencoba membuat jemaat Korintus terpecah.

Kedua, menghancurkan dengan hikmat dunia. Dalam perikop 1 Korintus 3:10-23, Paulus menegur orang yang menyangka dirinya bijaksana atau berhikmat menurut dunia. Allah membenci hikmat manusia itu sebabnya dikatakan dalam ayat 19 bahwa hikmat dunia adalah kebodohan bagi Allah. Adanya orang-orang yang mengandalkan hikmat 
manusia dalam jemaat Korintus membuat mereka tidak percaya akan kematian dan kebangkitan Yesus. Itu sebabnya salah satu masalah yang terjadi di jemaat Korintus pada saat itu adalah ketidakpercayaan mereka terhadap kebangkitan orang mati, berarti mereka tidak percaya akan kebangkitan Yesus dari antara orang mati.

Kedua makna frasa membinasakan di atas memiliki implikasi dengan kehidupan jemaat Kristen masa kini, antara lain:

Pertama, Jemaat Kristen harus hidup sesuai ajaran firman Tuhan. Firman TUhan punya pengaruh besar dalam hidup jemaat. ${ }^{12}$ Hidup sesuai ajaran firman Tuhan adalah belajar akan kebenaran firman Tuhan, antara lain membaca, merenungkan dan yang terpenting adalah melakukannya. Jemaat yang tidak tau kebenaran firman Tuhan akan mudah sekali untuk disesatkan dengan ajaran-ajaran yang tidak sesuai dengan kebernaran firman Tuhan. Itu sebabnya dalam suatu jemaat sangat penting untuk mengadakan penelaahan Alkitab (PA) agar jemaat dilatih untuk belajar Alkitab dengan benar.

Kedua, Jemaat Kristen harus hidup dalam kerendahan hati. Agar terciptanya jemaat yang satu di dalam Kristus dibutuhkan kerendahan hati dari setiap jemaat Tuhan, dimana didalamnya ada sikap saling menghargai dan menghormati satu dengan yang lain. Tanpa kerendahan hati hubungan antara anggota jemaat akan hancur, sikap saling menghakimi dan tidak menghargai adalah wujud tidak adanya kerendahan hati dalam jemaat. Oleh sebab itu kerendahan hati sangat penting demi menjaga kersatuan jemaat Kristen sehingga tidak terjadi perpecahan.

Ketiga, Jemaat Kristen harus hidup dalam Hikmat Allah. Dunia mulai dipengaruhi dengan hal-hal sekuler. ${ }^{13}$ Jemaat Tuhan seharusnya memiliki fokus hidup yang terbaik, yaitu selalu hidup dalam hikmat Allah. Karena sangat jelas dalam 1 Korintus 3:19-20 bahwa hikmat dunia itu adalah suatu kebodohan bagi Allah dan hikmat dunia itu hanyalah suatu kesia-siaan belaka. Dalam Yakobus 3:14-16 menjelaskan bahwa hikmat dunia itu berasal dari manusia dan setan-setan yang akan menghasilkan kekacauan dan segalah macam perbuatan jahat. Sedangkan hikmat dari Allah itu murni dan ditandai dengan buahbuah yang baik (Yak. 3:17-18). Jadi ketika jemaat Tuhan hidup dalam hikmat Allah, pasti akan terjadi kedamaian dalam jemaat. Hikmat Allah dapat diperoleh dari Allah saja yaitu dengan memintanya dengan iman (Yak. 1:5-6).

\section{Saran-saran}

Sesuai dengan pembahasan di atas maka penulis akan mengemukakan beberapa saran, antara lain:

Pertama, bagi para hamba-hamba Tuhan, secara khusus yang menggembalakan jemaat, agar memberikan pengertian yang jelas tentang arti yang benar mengenai bait Allah, menjelaskan kepada jemaat bahwa mereka adalah bait Allah, sangat penting untuk menjaga kesatuan dalam jemaat Allah. Para gembala juga harus memperhatikan kehidupan kerohanian jemaatnya, dan berusaha untuk terus membimbing jemaat agar mencapai kedewasaan rohani, bukan kerohanian yang stagnan.

Kedua, bagi jemaat Tuhan yaitu kumpulan orang-orang yang percaya kepada Yesus agar memperhatikan dan mengerti konsep bait Allah tersebut. Jemaat Kristen harus berusaha untuk menjaga kesatuan dalam hidup berjemaat dengan cara memiliki

\footnotetext{
${ }^{12}$ Serli dan Wijaya, 17.

${ }^{13}$ Objantoro, 56
} 
kerendahan hati, sehingga timbul rasa saling menghargai dan menghormati dalam jemaat. Perlu juga jemaat Kristen harus membangun kehidupan kerohanian secara khusus hidup dalam kerebaran firman Tuhan dengan belajar dimana didalamnya jemaat bisa mambaca, merenungkan dan melakukan kebanaran firman Tuhan sehingga tidak mudah untuk diombang-ambingkan dengan berbagai pengajaran-pengajaran sesat, dan tidak mudah juga terjadinya perselisihan dan perpecahan dalam jemaat.

Ketiga, bagi sekolah-sekolah Teologi agar benar-benar mempersiapkan mahasiswamahasiswi dengan pengajaran-pengajaran yang sesuai dengan kebenaran firman Tuhan, mahasiswa harus dibentuk dan diajarkan agar terus belajar kebenaran firman Tuhan dan juga bertumbuh dalam kerohanian, sehingga ketika mereka menyelesaikan studi dan melayani di manapun, mereka tetap mengajarkan atau mengabarkan kebenaran firman Tuhan dengan baik yang sesuai dengan kehendak Tuhan. sehingga mereka tidak memberitakan pengajaran-pengajaran yang salah, yaitu pengajaran yang tidak sesuai dengan firman Tuhan, melainkan memberitakan firman Tuhan sesuai dengan kehendak Tuhan sendiri.

\section{Kepustakaan}

Adewuya, J. Ayodeji. Holiness in the Letters of Paul. USA: Cascade Books, 2016.

Alkitab. Jakarta: Lembaga Alkitab Indonesia, 2013.

Anderson, Roger Dean. Tafsiran Perjanjian Baru Surat 1 Korintus. Surabaya: Momentum, 2018.

Baker, David L. Roh dan Kerohanian dalam Jemaat: Tafsiran Surat 1 Korintus. Jakarta: BPK Gunung Mulia, 1991.

Barclay, William. Pemahaman Alkitab Setiap Hari Surat $1 \& 2$ Korintus. Jakarta: BPK Gunung Mulia, 2008.

Bergant, Dianne, dan Robert J. Karris. Tafsiran Alkitab Perjanjian Baru. Yogyakarta: Kanisius, 2002.

BibleWorks 7.

Blomberg, Craig L. NIV Application Commentary: 1 Corinthians. Grand Rapids: Zondervan, 1995.

Boice, James Montgomery. Dasar-Dasar Iman Kristen. Surabaya: Momentum, 2015.

Browning, W. R. F. Kamus Alkitab. Jakarta: BPK Gunung Mulia, 2009.

Danker, Frederick William. A Greek-English Lexicon of the New Testament and other early Christian Literature. USA: The University of Chicago, 2000.

Ellingworth, Paul, dan Howard Hatton. Pedoman Penafsiran Alkitab Surat Paulus Yang Pertama Kepada Jemaat di Korintus. Jakarta: Lembaga Alkitab Indonesia, 2010. $e$-Sword the sword of the LORD with an electronic edge.

Guthrie, Donald. Teologi Perjanjian Baru I. Jakarta: BPK Gunung Mulia, 2008.

Heer, J. J. de. Tafsiran Alkitab: Kitab Wahyu Yohanes. Jakarta: BPK Gunung Mulia, 2008. Henry, Matthew. Tafsiran Matthew Henry SURAT ROMA, 1 \& 2 KORINTUS. Surabaya: Momentum, 2015.

Ibrahim, David. Pelajaran Surat 1 Korintus. Jakarta: Mimery Press, 1999.

Kee, Howard Clark, dkk. Alkitab Edisi Studi. Jakarta: Lembaga Alkitab Indonesia, 2015.

King, Philip J. Kehidupan Orang Israel Alkitabah. Jakarta: BPK Gunung Mulia, 2010.

Kristanto, Billy. Ajarlah Kami Bertumbuh. Surabaya: Momentum, 2009.

Latz, Andrew Brower, dan Arseny Ermakov. Purity: Essays in Bible and Theology. USA: Wipf and Stock Publishers, 2014. 
Lesmana, Herman, dan Robi Panggarra. "Makna Bait Allah dalam 1 Korintus 3:16-17 dan Implikasinya bagi orang Percaya Masa Kini." Jurnal Jaffray 12, no. 1 (2 April 2014): 128-56. https://doi.org/10.25278/jj71.v12i1.35.

Maiaweng, Peniel C. D. Kelompok Penelaahan Alkitab. Makassar: Sekolah Tinggi Theologia Jaffray, 2013.

Moo, Douglas J., Ralph P. Martin, dan Julie L. Wu. Romans-Galatians. Grand Rapids: Zondervan Academic, 2011.

Morris, Leon. The First epistle of Paul to the Corinthians: An Introduction and Commentary. Grand Rapids: Wm. B. Erdmans Publishing Company, 1999.

Newman, Willis C. How to Study the Bible. USA: Willis Newman, 2010.

Objantoro, Enggar. "Augustine's Theological Method And Contribution to the Christian Theology." International Journal of Indonesian Philofophy \& Theology 1, no. 1 (Juni 2020): 56-63. https://doi.org/10.47043/ijipth.v1i1.2

Park, Abraham. Imam Besar Kekal yang Dijanjikan dengan Sumpah. Depok: Yayasan Damai Sejahtera Utama, 2017.

Pfeiffer, Charles F., dan Everett F. Harrison. Tafsiran Alkitab Wycliffe. Malang: Gandum Mas, 2001.

Pfitzner, V. C. Kesatuan dalam Kepelbagaian. Jakarta: BPK Gunung Mulia, 2006.

Rajo, Gabriel Yobert. "Dosa Yerusalem dalam Yehezkiel 22:1-31: Kajian Biblika dan Implikasi Praktis." Jurnal Ilmu Teologi dan Pendidikan Agama Kristen 1, no. 2 (Desember 2020): 144-162. https://ojs.sttjaffray.ac.id/jitpk/article/view/518.

Ridderbos, Herman. Paulus: Pemikiran Utama Theologinya. Surabaya: Momentum, 2008.

SABDA OLB versi Indonesia

Serli dan Hengki Wijaya. "Metode Permainan dalam meningkatkan Pemahaman Firman Tuhan pada Remaja GKII Okahapi Sumba Timur.” Jurnal Ilmu Teologi dan Pendidikan Agama Kristen 1, no. 1 (Juni 2020): 17-28. http://dx.doi.org/10.25278/jitpk.v1i1.459.

Soards, Marion L. Understanding the Bible Commentary Series 1 Corinthians. United States of America: Baker Books, 2011.

Suawa, Ferdinan K. Memahami Gramatika Dasar Bahasa Yunani Koine. Bandung: Kalam Hidup, 2009.

Susanta, Yohanes Krismantyo. Harapan di Tengah Penderitaan: Anak Manusia dalam Daniel 7 dan Hubungannya dengan Injil Sinoptik. Yogyakarta: Kanisius, 2019.

Susanto, Hasan. Perjanjian Baru Interlinear Yunani-Indonesia dan Konkordansi Perjanjian Baru (PBIK) Jilid II. Jakarta: Lembaga Alkitab Indonesia, 2004.

Sutama, Adji A. Yesus Tidak Bangkit? Menyingkap Rekayasa Yesus Historis dan Makam Talpoit. Jakarta: BPK Gunung Mulia, 2007.

Tabb, Mark. Mari Berpikir tentang Alkitab: Apa Yang Tertulis di Dalamnya? Yogyakarta: Yayasan Gloria, 2011.

Vang, Preben. I Corinthians. United States of America: Baker Books, 2014.

Warren, Rick. The Purpose Driven Life- What on Earth Am I Here for? Jakarta: Immanuel Publishing House, 2015.

Wiersbe, Warren W. Hikmat Di Dalam Kristus. Bandung: Kalam Hidup, 2001. 